Electronic Supporting Information for

\title{
Preparation, Crystal Structures and Properties of Half-Sandwich Ruthenium Complexes Containing Salicylbenzoxazole Ligands
}

YING SUN, YUAN-CHEN DAI, XUE WANG, JIA-MING CHENG, WEI-GUO JIA*

College of Chemistry and Materials Science, Center for Nano Science and Technology, The Key Laboratory of Functional Molecular Solids, Ministry of Education, Anhui Laboratory of Molecular-Based Materials, Anhui Normal University, Wuhu, 241000, China

* Corresponding author. wgjiasy@mail.ahnu.edu.cn, 
$\mathrm{OH} \quad \mathrm{N}$

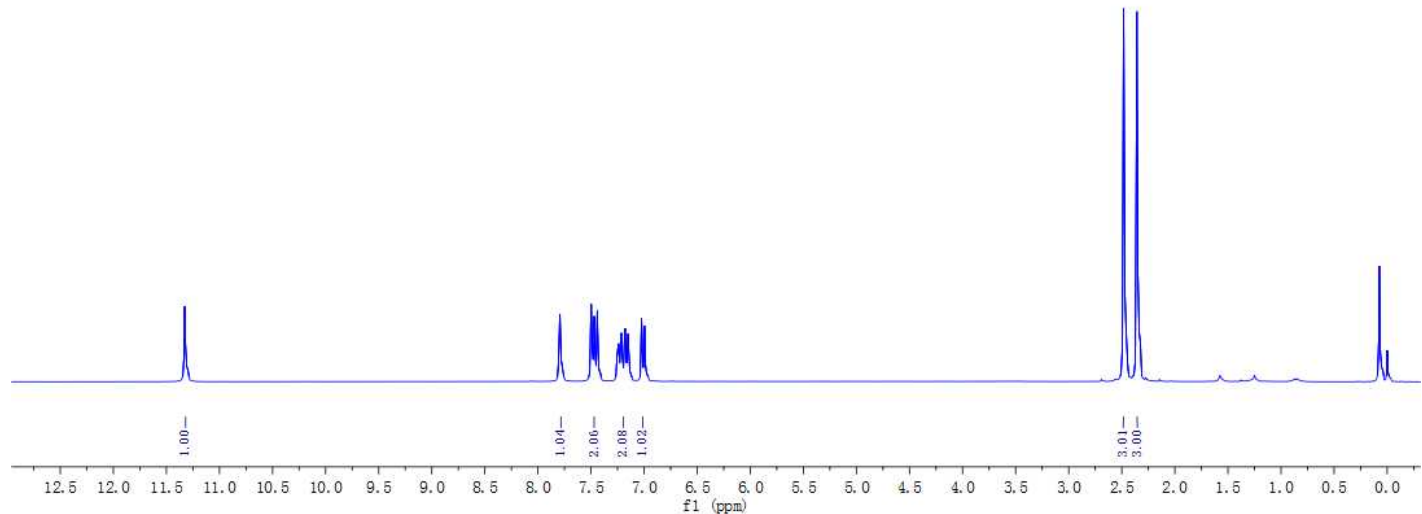

${ }^{1} \mathrm{H}$ NMR spectrum of $\mathbf{1 a}$

$\mathrm{OH}$
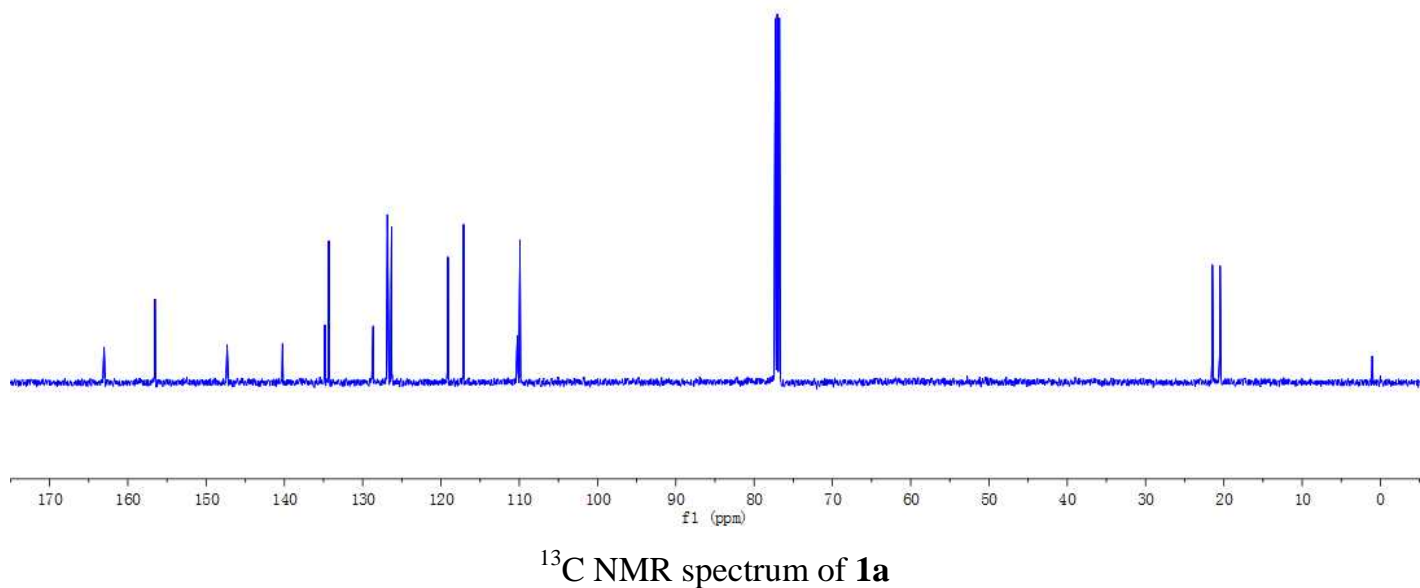
$\mathrm{OH} \mathrm{N}$

o

cl

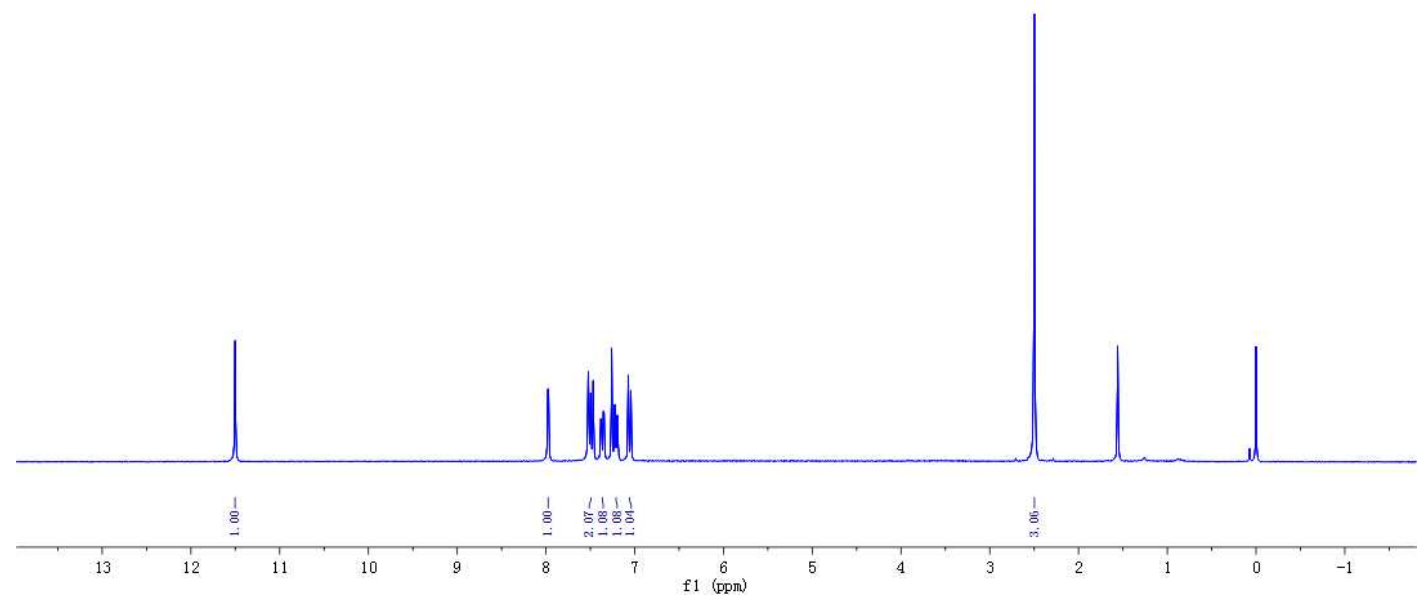

${ }^{1} \mathrm{H}$ NMR spectrum of $\mathbf{1 b}$
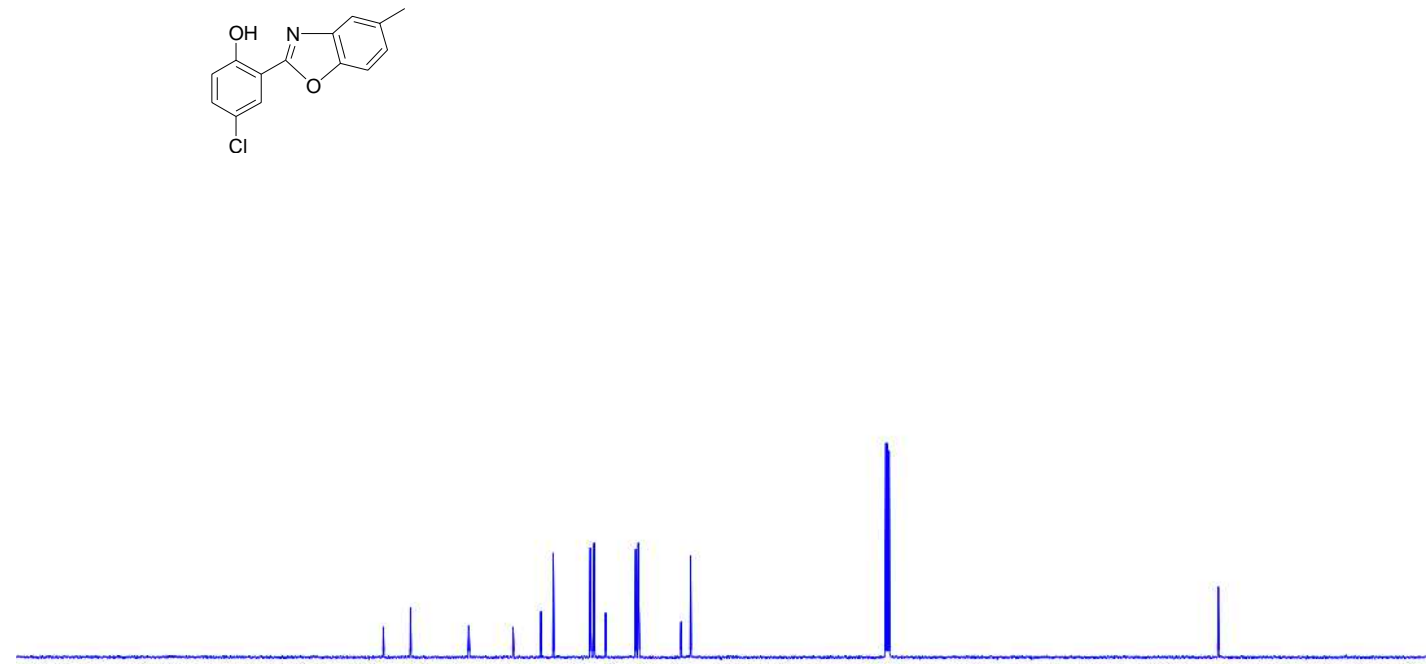

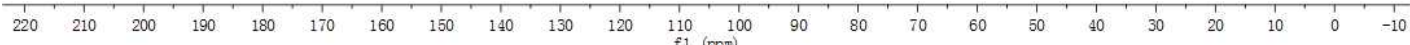

${ }^{13} \mathrm{C}$ NMR spectrum of $\mathbf{1 b}$ 


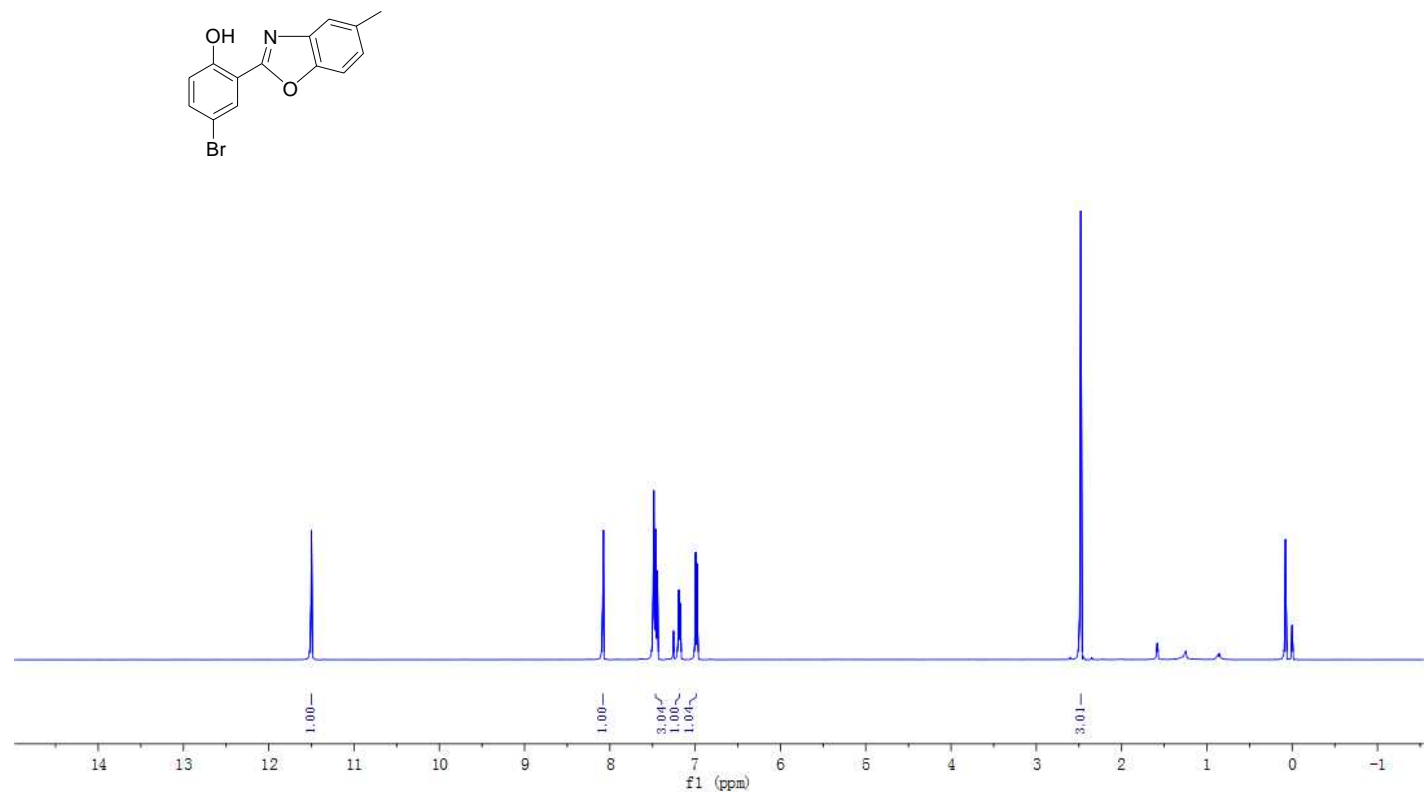

${ }^{1} \mathrm{H}$ NMR spectrum of $\mathbf{1 c}$

$\mathrm{OH} \quad \mathrm{N}$

$\mathrm{Br}_{\mathrm{Br}}$
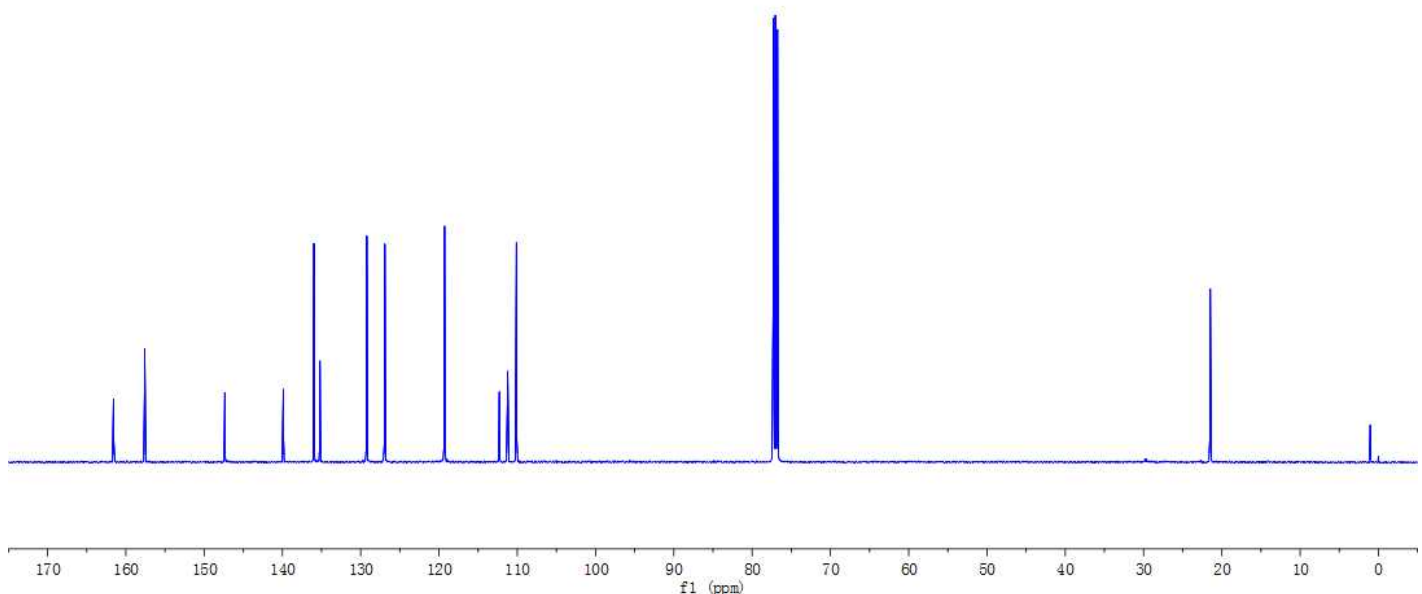

${ }^{13} \mathrm{C}$ NMR spectrum of $\mathbf{1 c}$ 


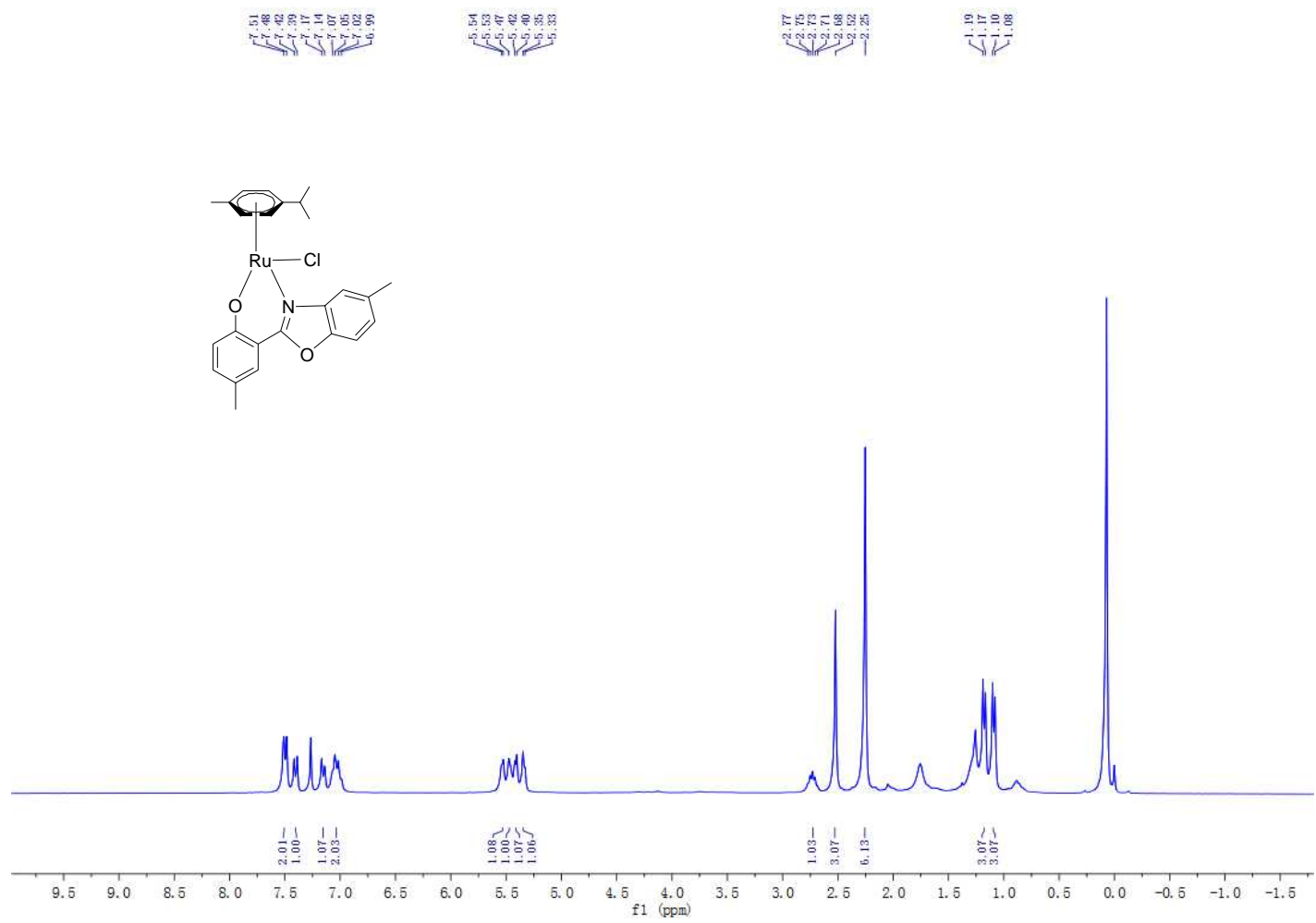

${ }^{1} \mathrm{H}$ NMR spectrum of $\mathbf{2 a}$

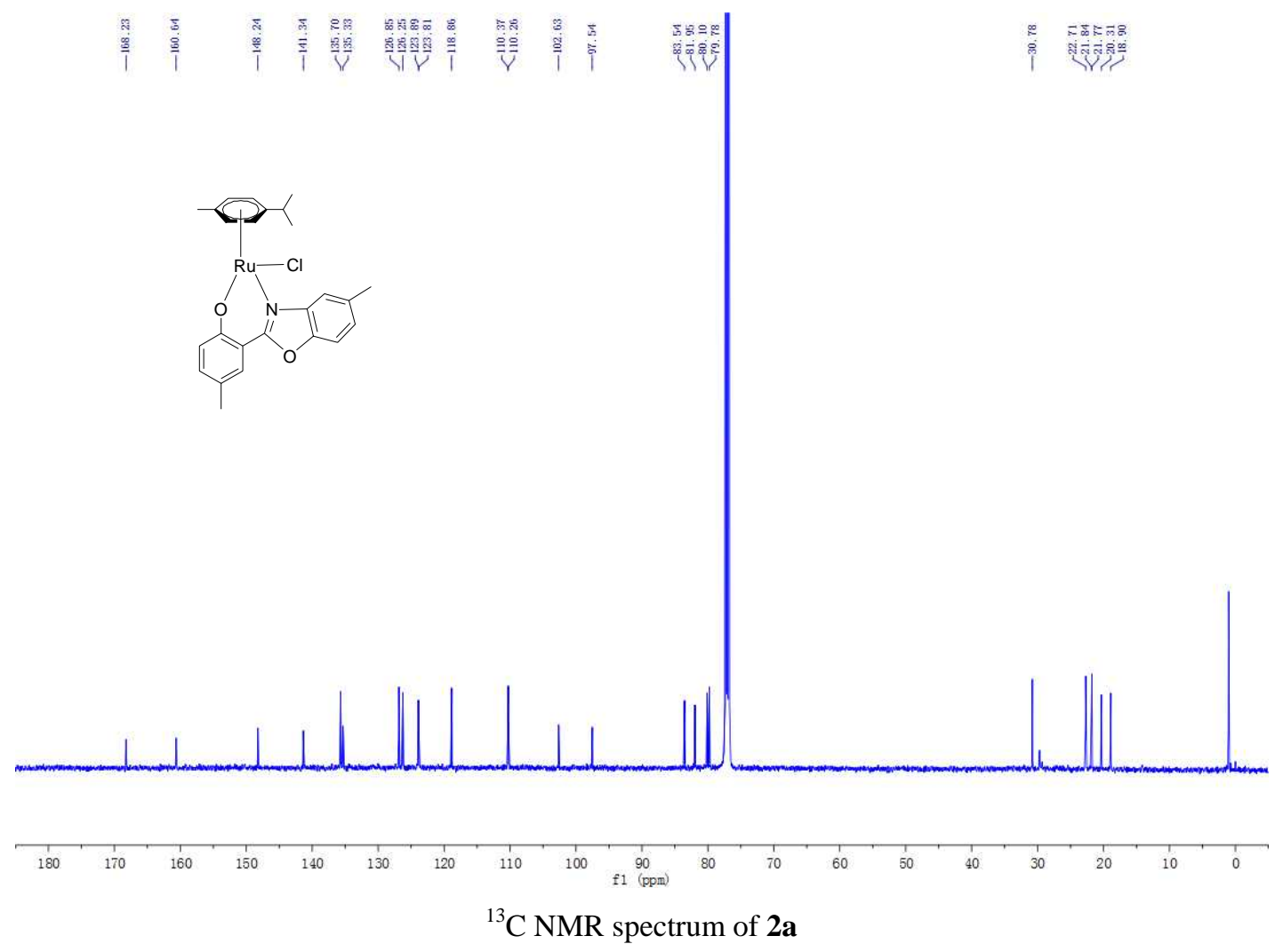




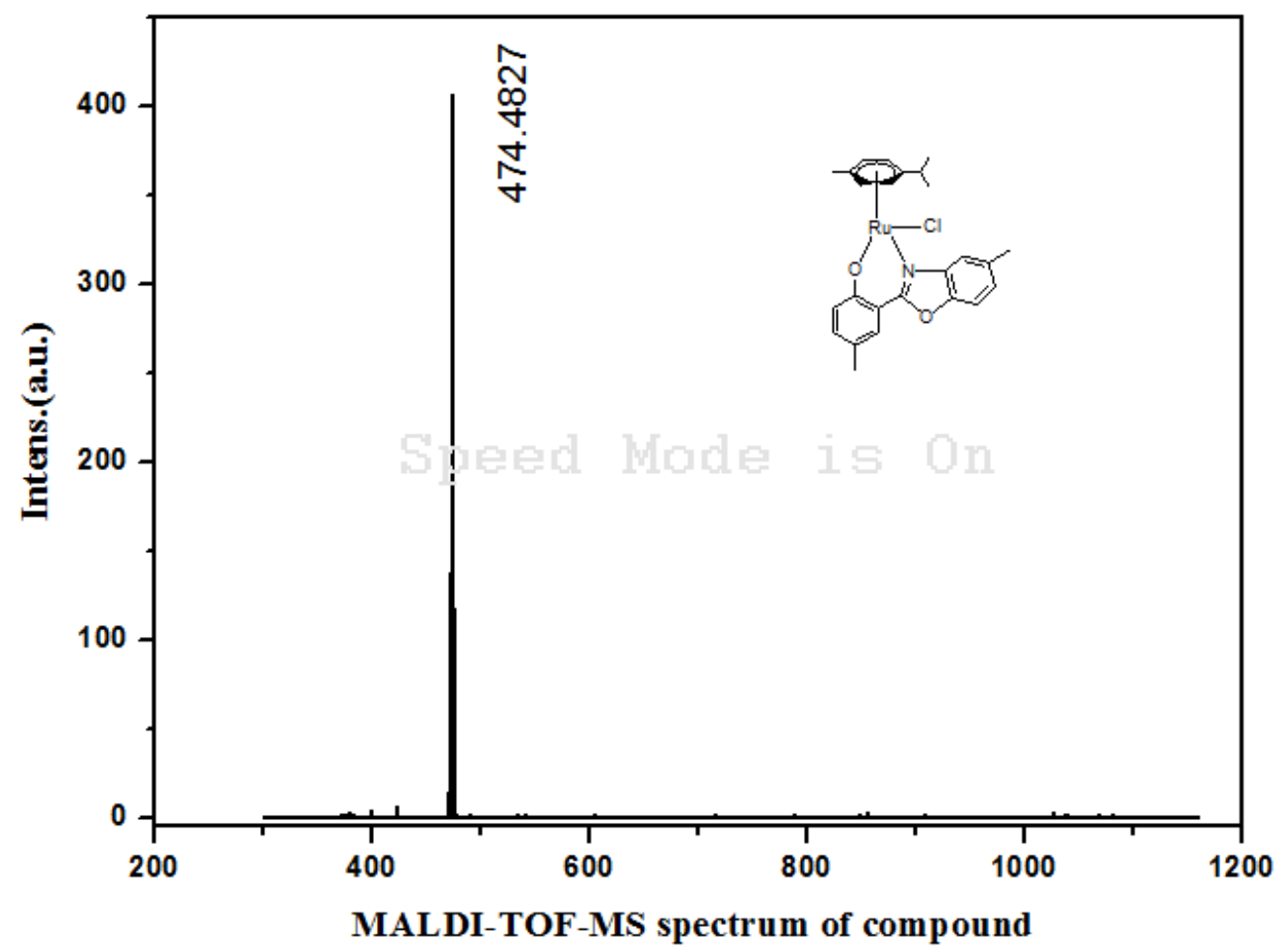

MS spectrum of [2a-Cl] ${ }^{+}$

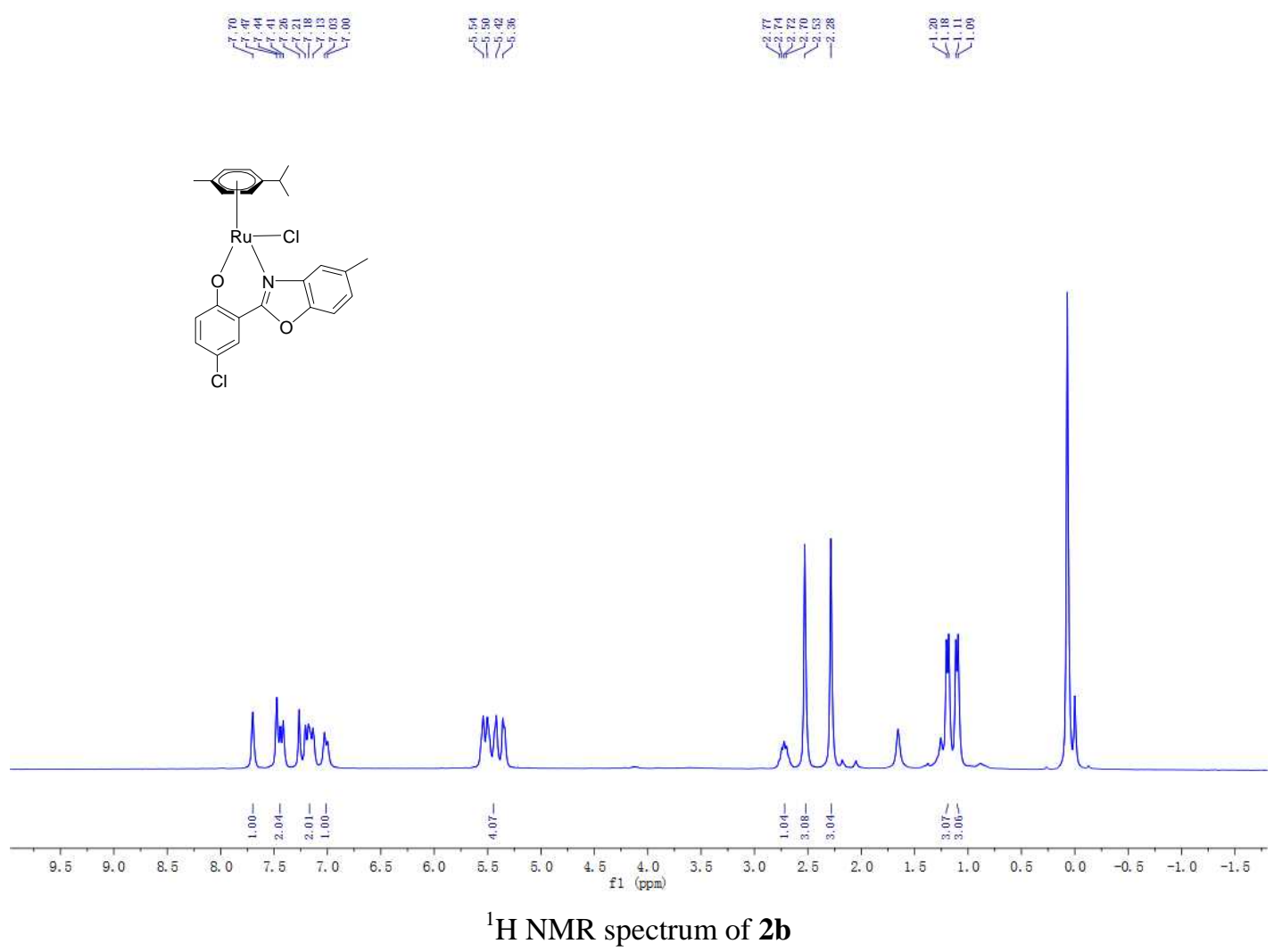



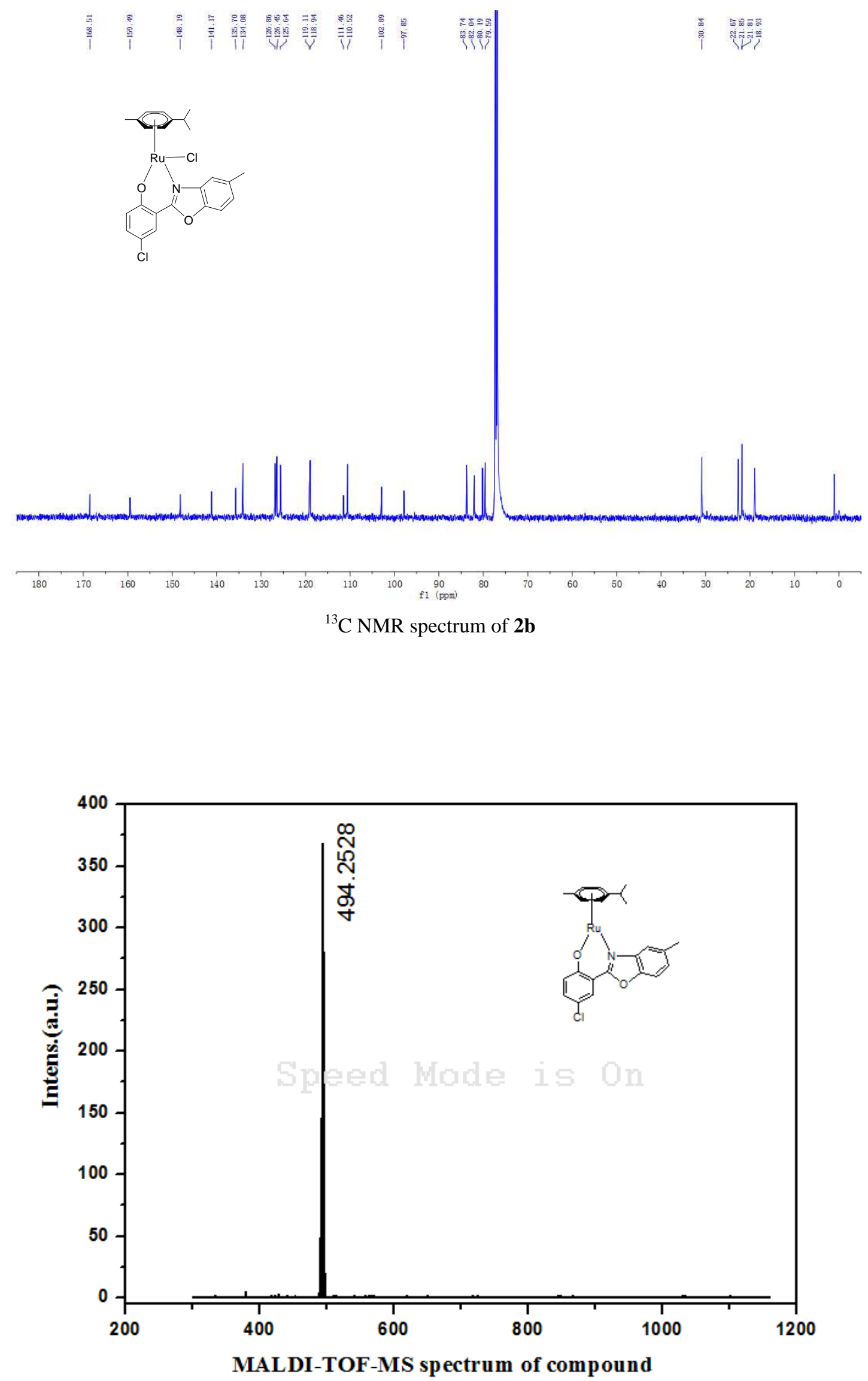

MS spectrum of [2 $\mathbf{b}-\mathbf{C l}]^{+}$ 


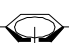

$\mathrm{Ru}-\mathrm{Cl}$

$\mathrm{O} N$

o

$\mathrm{Br}$

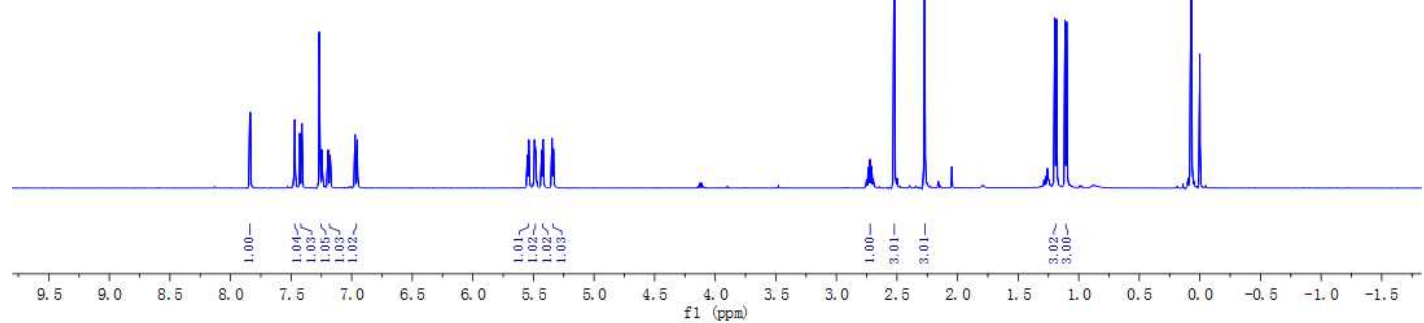

${ }^{1} \mathrm{H}$ NMR spectrum of $\mathbf{2 c}$
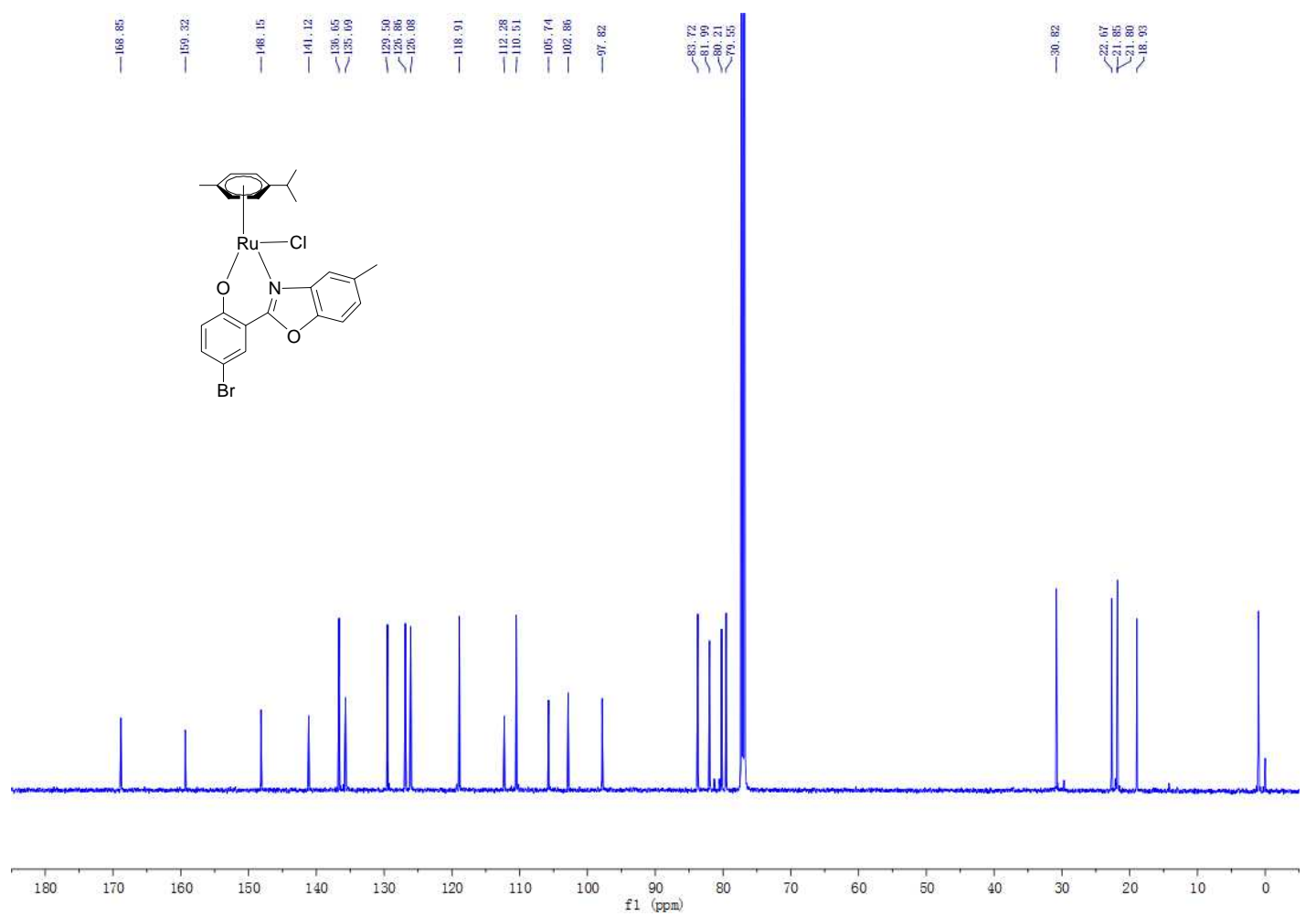

${ }^{13} \mathrm{C}$ NMR spectrum of 2c 


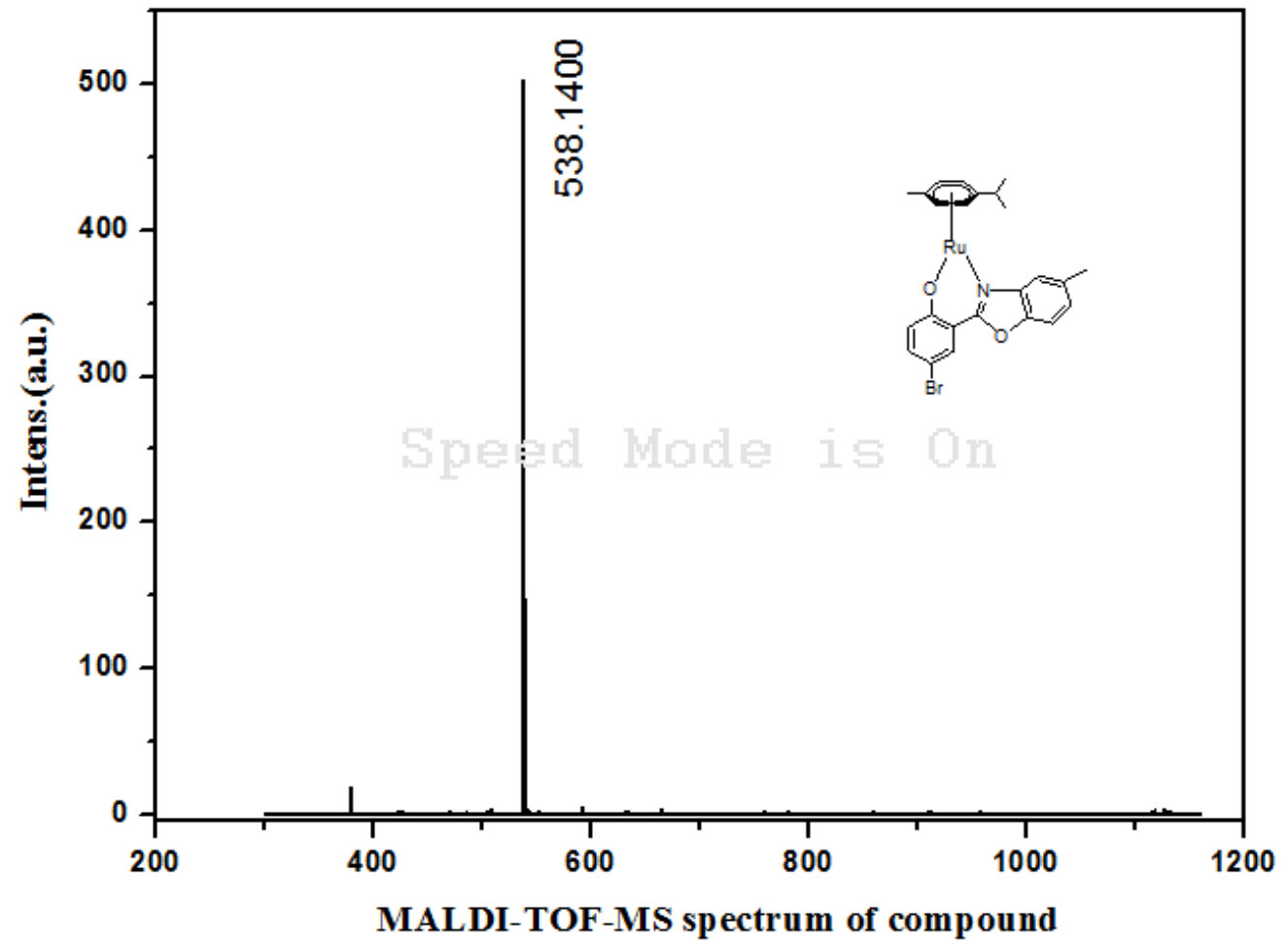

MS spectrum of [2c-Cl] $]^{+}$ 